\title{
Kinetic and influence factors on debromination of decabromodiphenyl ether by organo-montmorillonite supported nanoscale zero-valent iron
}

\author{
Zhihua Pang $^{\mathrm{a}}{ }^{\text {, }}$, Jinrong Qiu ${ }^{\mathrm{b}}, \mathrm{Li} \mathrm{Liu}^{\mathrm{c}}$ and Yutao Lei ${ }^{\mathrm{d},{ }^{*}}$ \\ South China Institute of Environmental Sciences, MEP, Guangzhou 510655, China \\ a Zh.pang@qq.com, b31403332 @qq.com, ${ }^{c} 153704469$ @qq.com, d,"184341060 @qq.com \\ * Yutao Lei
}

Keywords: kinetic, influence factors, supported nanoscale zero-valent iron, decabromodiphenyl ether, degradation.

Abstract. The organo-montmorillonite supported nanoscale zero-valent iron material (M-NZVI) was synthesized to degradate decabromodiphenyl ether (BDE-209). The kinetic and influence factors of apparent rate constant on debromination of BDE-209 by M-ZVI were studied, the experiment was conducted to investigate the influences of initial concentration, different materials dogs and $\mathrm{pH}$ value. The results show that all reaction processes followed pseudo first order kinetic equation, The apparent rate constant increased respectively with the increase of initial concentration, different materials dogs and the decrease of $\mathrm{pH}$ value.

\section{Introduction}

Polybrominated diphenyl ethers (PBDEs) widely used in electronic, chemical, electrical, textile, and other industries as a typical kind of brominated flame retardants[1], are ubiquitous in the environment, with high hydrophobicity, persistence, bioaccumulation and toxicity[2], among which BDE-209 is the only one that is still in production and large-scale use.It is a new way to degradate BDE-209 by M-ZVI, In this study, the kinetic and influence factors of apparent rate constant on debromination of BDE-209 by M-ZVI were studied, the experiment was conducted to investigate the influences of initial concentration, different materials dogs and $\mathrm{pH}$ value.

\section{Materials and methods}

\section{Preparation and characterization of materials \\ Preparation and characterization of M-ZVI materials reference this method[3]. \\ Process of batch experiment}

First, $50 \mathrm{~mL} \mathrm{BDE-209}$ mixed solution $\left(2.0 \mathrm{mg} \cdot \mathrm{L}^{-1}\right)$ were added into $100 \mathrm{~mL}$ conical flask with plug as a reactor, and adding the synthetic material. The reactor was then sealed and stirred with

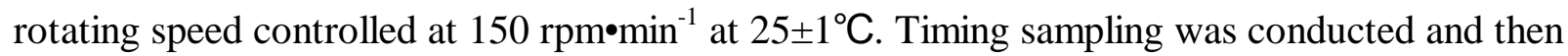
filtered, and the filtration was used for the analysis of the concentration of BDE-209. All samples were performed in four replications.

Influence factors of apparent rate constant include initial concentration, different materials dogs and $\mathrm{pH}$ value. Initial concentration of BDE-209 Solution is $1.0 \mathrm{mg} \cdot \mathrm{L}^{-1}, 2.0 \mathrm{mg} \cdot \mathrm{L}^{-1}$ and $5.0 \mathrm{mg} \cdot \mathrm{L}^{-1}$ respectively, the different materials dogs is $0.20 \mathrm{~g}, 0.40 \mathrm{~g}, 0.60 \mathrm{~g}$ and $0.80 \mathrm{~g}$ respectively, the different $\mathrm{pH}$ value is 3.0,5.5,7.0 and 9.0.

\section{Analytical method}

The concentration of BDE-209 was measured by HPLC (Shimadzu LC-20AT) equipped with a SupelcosilTMK C18 chromatographic column $(250 \mathrm{~mm} \times 4.6 \mathrm{~mm}, 5 \mu \mathrm{m})$ and detected by UV spectrophotometry at a wavelength of $204 \mathrm{~nm}$ and $226 \mathrm{~nm}$ in a mobile phase $(1.0 \mathrm{~mL} / \mathrm{min})$ composed of acetonitrile/water $=98 / 2(\mathrm{~V} / \mathrm{V})$. 
The concentration of bromide ion was determined by ion selective electrode method with instrument of Leici PHS-3C equipped with 301 bromide ion selective electrode and 801 double liquid junction saturated calomel electrode.

\section{Results and discussion}

\section{The sorption kinetic on debromination of BDE-209 by M-ZVI}

In the BDE-209 water solution, the surface which is contacted with the Nano iron particles and the BDE-209 water solution is called the Solid-liquid two phase interface, it is the place which Nano iron reducted BDE-209 to carry out the reaction of bromine.So the reaction steps of the debromination of BDE-209 by M-ZVI is similar to the steps of the debromination of halogen organic pollutants by M-ZVI, and the results of most scholars study show that all reaction processes of BDE-209 and the Nano iron (or other metals) followed Pseudo first order kinetic equation[4,5,6].So pseudo first order kinetic equation is fitted for reaction process of it. The Equation is allowed.

$$
\ln \frac{C_{B D E-209}}{C_{0 B D E-209}}=-k_{\text {obs }} t
$$

In the formula, $\mathrm{t}$ is the reaction time, the unit is $\min$; the $\mathrm{k}_{\mathrm{obs}}$ is pseudo first order kinetic reaction rate constant, the unit is $\min ^{-1} ; \mathrm{C}_{\mathrm{BDE}-209}$ is concentration of BDE-209 in the reaction time $t$, the unit is $\mathrm{mg} \cdot \mathrm{L}^{-1}, \mathrm{C}_{0 \mathrm{BDE}-209}$ is the initial concentration of BDE-209, the unit is $\mathrm{mg} \cdot \mathrm{L}^{-1}$.In this study, M-NZVI and NZVI were chose to fit the degradation kinetics of BDE-209, the curve fitting graph is shown in Fig.1.

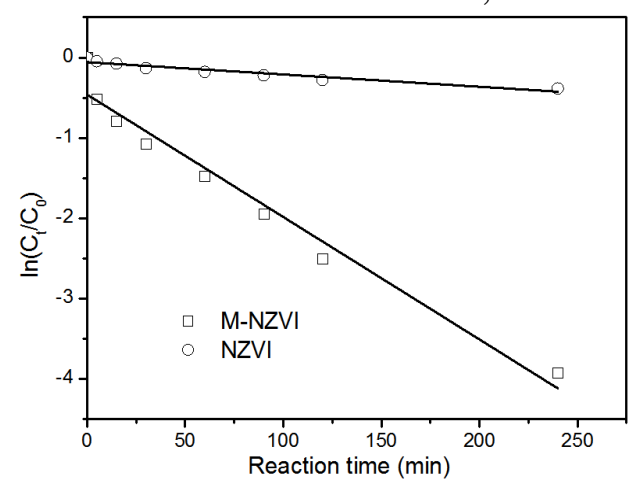

Fig.1 The kinetic fitting on BDE-209 removal of M-NZVI and NZVI

The results of Fig.1 show that the reaction processes of BDE-209 by M-NZVI and NZVI all follow pseudo first order kinetic equation, and it Has a good linear relationship, $\mathrm{R}^{2}$ is 0.9622 and 0.9083 respectively. The apparent rate constant of the degradation of BDE-209 by M-NZVI and NZVI were $1.525 \times 10^{-2}$ and $0.153 \times 10^{-2}$ respectively, the apparent rate constant of NZVI materials for 9.96 times that of NZVI, and it shows that M-NZVI material has higher reactivity.

The influence of different factors on the apparent rate constant

(1) The influence of initial concentration of BDE-209 on the apparent rate constant

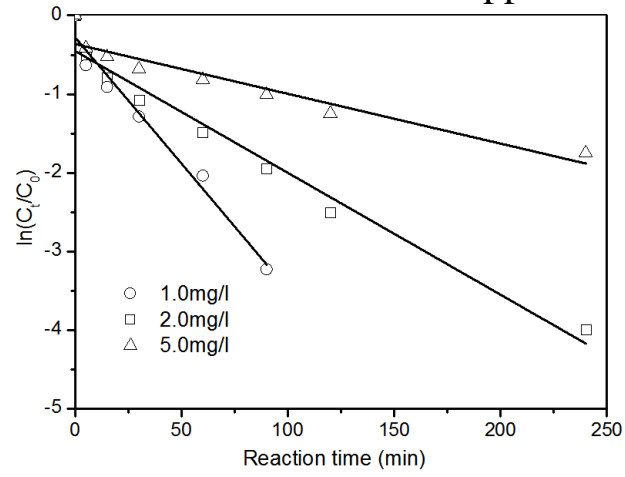

Fig.2 The kinetic fitting on BDE-209 removal of M-NZVI with different initial concentration 
The results of Fig. 2 show that the reaction processes of initial concentration of BDE-209 by M-NZVI follow pseudo first order kinetic equation. When the initial concentration of BDE-209 were $1.0 \mathrm{mg} \cdot \mathrm{L}^{-1}, 2.0 \mathrm{mg} \cdot \mathrm{L}^{-1}$ and $5.0 \mathrm{mg} \cdot \mathrm{L}^{-1}$, its $\mathrm{k}_{\text {obs }}$ were $2.821 \times 10^{-2}, 1.550 \times 10^{-2}$ and $0.633 \times 10^{-2}$, the results show that with the increase of initial concentration of BDE-209, the apparent reaction rate constant gradually reduce, so the degradation reaction rate of BDE-209 by M-NZVI gradually reduced, the result is consistent with the research results of many scholars[4,5,6]. For a certain amount of M-NZVI material, the total effective reactive sites in its material number is certain, with the increase of pollutants concentration, the reactive sites by all gradually occupy, and BDE-209 between molecules due to the increase in the number and there is more competition, leading to removal rate is reduced, so the rate constant kobs gradually reduced.

(2) The influence of different materials dogs of M-ZVI on the apparent rate constant

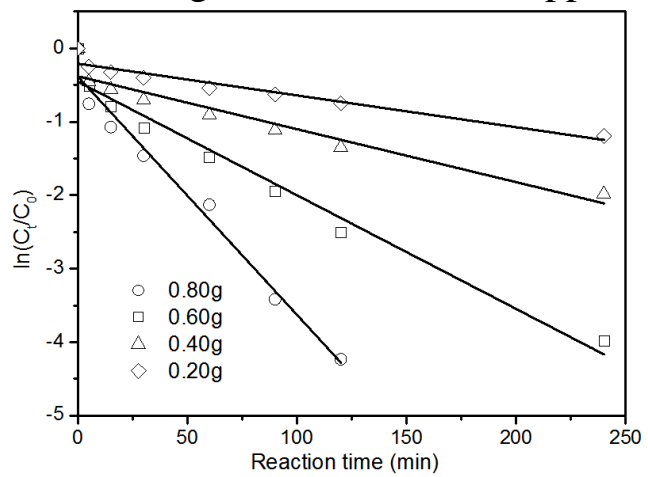

Fig.3 The kinetic fitting on BDE-209 removal of M-NZVI with different materials dogs

The results of Fig. 3 show that the reaction processes of different materials dogs of M-ZVI follow pseudo first order kinetic equation too. When the M-NZVI dogs were $0.20 \mathrm{~g}, 0.40 \mathrm{~g}$ and $0.60 \mathrm{~g}$ and $0.80 \mathrm{~g}$, the apparent reaction rate constant gradually increases, its $\mathrm{k}_{\mathrm{obs}}$ were $0.433 \times 10^{-2}$, $0.721 \times 10^{-2}, 1.548 \times 10^{-2}$ and $2.245 \times 10^{-2}$ respectively, the results show that with the increase of M-NZVI dogs, the degradation reaction rate of BDE-209 by M-NZVI increased, the result is consistent with the research results of many scholars[7,8]. M-NZVI material cast will increase with the increase of the amount is the total specific surface area, is also increase the material in the total number of reactive sites effectively, increased the number of reactive sites to BDE-209 adsorption and reduction of pollutants, leading to removal rate increases, so the rate constant gradually rise.

(3) The influence of the initial reaction solution $\mathrm{pH}$ value on the apparent rate constant

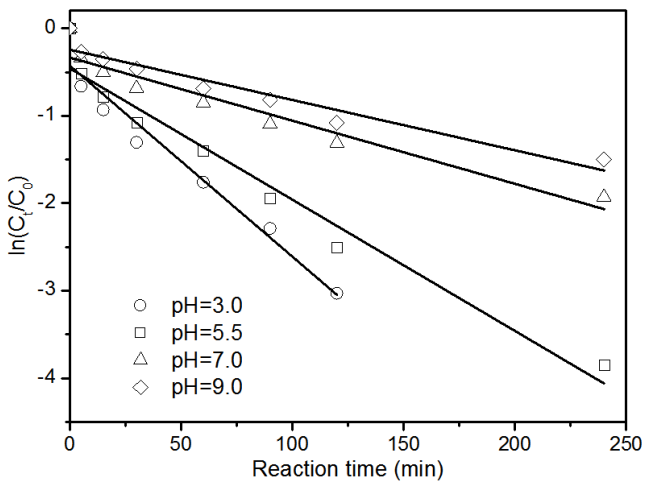

Fig. 4 The kinetic fitting on BDE-209 removal of M-NZVI with different $\mathrm{pH}$

The results of Fig.4 show that the reaction processes of the initial reaction solution $\mathrm{pH}$ value of M-ZVI follow pseudo first order kinetic equation too, the initial reaction solution $\mathrm{pH}$ value have bigger influence on the apparent reaction rate constant, $\mathrm{k}_{\mathrm{obs}}$ value decrease with increasing initial $\mathrm{pH}$ value of reaction solution. When the initial reaction solution $\mathrm{pH}$ value were 3.0,5.5,7.0 and 9.0, its $\mathrm{k}_{\mathrm{obs}}$ were $2.184 \times 10^{-2}, 1.502 \times 10^{-2}, 0.722 \times 10^{-2}$ and $0.576 \times 10^{-2}$ respectively, of the apparent reaction rate constant when $\mathrm{pH}$ value is 3.0 is three times of which $\mathrm{pH}$ value is 9.0. The results show that the acid 
environment conducive to the degradation of BDE-209 by M-NZVI material, in the acidic conditions of BDE-209 rapid reaction rate, the result is similar with many scholars research results[9,10]. It also shows that acid environment can prevent the formation of iron oxide and hydroxide precipitation, promote zero-valent iron surface and BDE-209 electron transfer between the pollutants, which was beneficial to the improvement of the degradation effect of BDE-209, so the apparent reaction rate constant reduce with the increase of $\mathrm{pH}$ value.

\section{Summary}

(1) The results on the debromination of decabromodiphenyl etherby organo-montmorillonite supported nanoscale zero-valent iron show that all reaction processes followed pseudo first order kinetic equation.

(2)The apparent rate constant increased respectively with the increase of initial concentration, different materials dogs and the decrease of $\mathrm{pH}$ value.

\section{Acknowledgment}

The authors are grateful for the financial support provided by the National Science and Technology Major Projects of Water Pollution Control and Management of China (2012ZX07206002).

\section{References}

[1] Y. Luo, X. J. Luo, Z. Lin et al., Polybrominated diphenyl ethers in road and farmland soils from an e-waste recycling region in Southern China: concentrations, source profiles, and potential dispersion and deposition, Science of the Total Environment. 407(2009 ) 1105-1113.

[2] K. Law, T. Halldorson, R. Danell et al., Bioaccumulation and trophic transfer of some brominated flame retardants in a Lake Winnipeg (Canada) food web,Environmental Toxicology and Chemistry. 25 (2006)1283-1290.

[3] Z.H. Pang,M.Y. Yan,X.S. Jia et al.,Debromination of decabromodiphenyl ether by organo-montmorillonite supported nanoscale zero-valent iron: Preparation, characterization and influence factors, Journal of Environmental Sciences.26(2014)483-491.

[4] Z.Q. Fang, X.H. Qiu, J.H. Chen et al., Degradation of the polybrominated diphenyl ethers by nanoscale zero-valent metallic particles prepared from steel pickling waste liquor,Desalination .267(2011):34-41.

[5] Y. Zhuang, S. Ahn, R.G. Luthy. Debromination of polybrominated diphenyl ethers by nanoscale zero-valent iron: pathways, kinetics, and reactivity,Environmental Science and Technology, 44(2010)8236-8242.

[6] Y.H. Shih, Y.T. Tai. Reaction of decabrominated diphenyl ether by zero-valent iron nanoparticles, Chemosphere .78 (2010)1200-1206.

[7] Z.Q. Fang, X. Qiu, J. Chen,Debromination of polybrominated diphenyl ethers by Ni/Fe bimetallic nanoparticles: Influencing factors, kinetics, and mechanism,Journal of Hazardous Materials.185(2011) 958-969.

[8] Y. Zhuang, L. Jin, R.G.Luthy, Kinetics and pathways for the debromination of polybrominated diphenyl ethers by bimetallic and nanoscale zerovalent iron: effects of particle properties and catalyst,Chemosphere,89(2012) 426-432.

[9] H. Zhu, Y. Jia, X. Wu et al., Removal of arsenic from water by supported nano zero-valent iron on activated carbon, Journal of Hazardous Materials.172(2009) 1591-1596. 
[10] Y, Zhang, Y. Li, X. Zheng, Removal of atrazine by nanoscale zero valent iron supported on organobentonite, Science of the Total Environment. 409(2011) 625-630. 